\title{
Bully victim identification and intervention program for school nurses-A case study
}

\author{
Nora Zinan \\ Department of Nursing, University of Saint J oseph, United States \\ Correspondence: Nora Zinan. Address: University of Saint Joseph, 1678 Asylum Avenue, West Hartford, CT 06117, \\ United States. Email: nzinan@usj.edu
}

Received: August 3, 2013

Accepted: December 3, 2013

Online Published: December 11, 2013

DOI : $10.5430 /$ cns.v2n1p45

URL: http://dx.doi.org/10.5430/cns.v2n1p45

\begin{abstract}
The repeated acts of intimidation that occur with bullying have serious psychological and physical health consequences for victims and their bullies. Bullying involvement has been shown to predict student visits to the school health office with somatic complaints, illness, and injury. However, school nurses feel unprepared and unqualified to deal with bullying issues. This paper presents the results of an educational program designed to train school nurses to identify victims and bullies, and to intervene. A convenience sample of eleven nurses from ten schools in three districts in Western Massachusetts completed a questionnaire prior to, immediately following, and one month after the educational program. All reported an increase in their ability to recognize the signs and symptoms of bullying behavior and the effects on their victims. The nurses indicated a greater likelihood of aiding victims as a result of the program. Educating nurses empowers them to respond to bullying.
\end{abstract}

\section{Key words}

Bullying, School nursing, Education

\section{I ntroduction}

Bullying is a major public health concern in the United States (US), occuring in $23 \%$ of schools on a daily or weekly basis ${ }^{[1]}$. It is characterized by repeated physical or psychological intimidation that can have longstanding effects for victims and bullies alike ${ }^{[2-4]}$. Physical bullying presents as "hitting, kicking, spitting, pushing and taking personal belongings". Verbal abuse is defined as "taunting, malicious teasing, name calling, making threats" and relational bullying as "spreading rumors, manipulating social relationships, or engaging in social exclusion, extortion, or intimidation" ${ }^{[5]}$ Cyberbullying includes humiliation, slander, taunts and misrepresentations that occur through the use of email, blogging, websites and messaging via computers and phones ${ }^{[6]}$.

Those involved with bullying have been identified in the literature as bullies, victims, coincidental bully-victims and bystanders ${ }^{[7-9]}$. Coincidental bully-victims are defined as being both victims of bullying as well as being perpetrators. Utilizing US data from the 2005-2006 Health Behavior in School-aged Children Survey, Wang, Iannotti and Nansel reported that $20.8 \%$ of students were involved with physical bullying as bullies, victims or bully-victims, $53.6 \%$ with verbal bullying, 51.4\% with relational bullying, and 13.6\% with cyberbullying ${ }^{[10,11]}$. The data from the 2011 Youth Risk 
Behavior Surveillance Survey (YRBSS) indicates that 20\% of high school students in the United States were bullied on school property in the 12 months preceding the survey, and $16 \%$ were electronically bullied ${ }^{[12]}$.

When bullying occurs in schools, it creates an unsafe environment and causes behavioral and emotional difficulties that can interfere with learning ${ }^{[7]}$. Bullies, victims and coincidental bully-victims may experience poorer psychosocial adjustment and academic achievement, fighting, smoking, poorer relationships with classmates, increased loneliness, alcohol use, poorer perceived school climate and difficulty making friends ${ }^{[8]}$. Victims of bullying are also more likely to be depressed and suicidal ${ }^{[7,13-15]}$.

Three groups of students are at high risk of being bullied: overweight/obese students, children with special health care needs, and gay/lesbian/bisexual youth. Overweight and obese boys and girls are more likely to be the victims of bullying than their normal-weight peers ${ }^{[16-18]}$. Van Cleave and Davis analyzed data from the 2003 administration of the National Center for Health Statistics telephone survey of 102,000 households in the US and found that after adjusting for socioeconomic variables, children with special health care needs (CSHCN) were significantly more likely to be bullied than those without special health care needs ${ }^{[19]}$. In a study of 96 college-aged gay men, Friedman and colleagues found a significant relationship between bullying victimization in elementary, middle or high school and suicidality ${ }^{[20]}$.

Research is limited regarding the role of school nurses and their encounters with students involved with bullying. Vernberg, Nelson, Fonagy and Twemlow correlate health office visits with bullying involvement both as a victim and a bully ${ }^{[21]}$. In a study of third through fifth graders, the authors conclude that victimization and perpetration are "significant and unique" predictors of illness visits related to somatic complaints, illnesses, and injuries. Greco and colleagues also found that children with frequent complaints of abdominal pain experienced higher levels of bullying victimization and utilized the school health services significantly more often than their pain-free peers ${ }^{[22]}$.

A whole-school approach has been identified as the most effective strategy to reduce or prevent bullying ${ }^{[23]}$. In order to effectively reduce bullying in schools, interventions must occur at every level of the bullying experience- the individual, class, and school levels. A whole-school approach incorporates a written anti-bullying policy, parent and teacher training to deal with bullying, student education about the dynamics of bullying in the form of a curriculum, and bystander intervention.

The National Association of School Nurses (NASN) and the American Academy of Pediatrics (AAP) state that school nurses should have a role in bullying prevention efforts ${ }^{[24,25]}$. However, when nurses were asked their perception of their role, $41 \%$ felt that someone else in the school was more qualified to address bullying and $25 \%$ felt unprepared to handle the problem. Only $15 \%$ of nurses stated there were no barriers to becoming involved with bullying prevention efforts ${ }^{[26]}$.

Since youth who are involved with bullying develop health symptoms and most likely present to the health office, it is important to support the school nurse's role in dealing with this issue. This paper presents the results of an educational program designed to train school nurses to identify victims of bullying and to intervene, the Bully Victim Identification and Intervention Program (BVIIP). The question asked by the program was, "Will educating nurses about bullying empower them to become involved in preventing it and intervening?”

\section{Methods}

Participants were recruited through the Western Mass Nurse Leaders' Meeting and professional contacts to attend the Bully Victim Identification and Intervention Program (BVIIP). Each subject attended one of two trainings offered after school. These hours were selected in order to attract a wider audience and eliminate costs for substitute nurses. Activities included a presentation, self-assessment of biases related to obesity and gay/lesbian/bisexual youth and small group discussions. The program objectives were to: 
- Discuss the prevalence of bullying in schools, the risk factors, and programs that can be used to prevent or reduce bullying

- Explore attitudes and beliefs about your role in preventing bullying

- Integrate knowledge about bullying into the understanding of the your role in preventing bullying

- Explore attitudes and beliefs about overweight/obese and Gay, Lesbian, Bisexual Youth as potential victims of bullying and how this may influence the your role

- Identify bully victims among visitors to the nurse's office

- Identify resources and ways to assist bully victims

The Ecological Perspective was used as a foundation for designing the program ${ }^{[27]}$. This theoretical framework emphasizes the multi-level nature of factors that contribute to a health problem and the need for intervention strategies to address all levels of influence ${ }^{[28]}$. Self-assessment activities addressed the individual level of intervention, while discussion addressed the interpersonal and community level factors.

Prior to the program, immediately following the program and 1 month after the training the nurses completed the Perceptions of Bullying questionnaire ${ }^{[26]}$. Face, content and construct validity were previously established by the questionnaire's original authors. For this study, the questionnaire was adapted by adding ten questions regarding beliefs about the effectiveness of interventions to reduce bullying. The format for asking these questions agreed with the original instrument. For example, in response to the question, "In general, how effective do you think each of the following would be in reducing bullying?" the phrase "Reporting data on how many students report to the nurse's office as victims of bullying" was one of the options added. Examples of other phrases included: "working with victims to improve social skills if that is a problem", "dealing with my personal feelings about bullying” and "educating the victim about the bully/victim dynamic". The language was pilot tested during the summer, and the Cronbach's alpha was 0.91 utilizing SPSS.

Evaluation of the training was accomplished by the administration of a program evaluation tool by Seigel and Yates ${ }^{\text {[29] }}$. The BVIIP was approved for 2.5 Contact Hours which were awarded to each nurse. Finally, a resource manual was given to each nurse at the end of the education intervention.

The purpose of this project is performance improvement and is not considered research.

Therefore, it was exempt from seeking Institutional Review Board permission. Anonymity was preserved by aggregating responses to the questionnaire and excluding names. Data specific to students was not obtained or distributed, in keeping with the Family Education Rights and Protection Act.

Data analysis included calculating frequencies for responses regarding the number of methods the nurses might use for dealing with bullies and victims, and perceived barriers to becoming involved. The percent increase in the number is reported.

Means and modes were calculated for Likert Scale questions regarding perceptions of bullying as a problem in the United States. Paired $t$-tests were performed utilizing SPSS to compare pre-program and averaged post-program means on questions 6 and 7 which dealt with the nurses' perceived ability to recognize the signs of a student being a bully or a victim. Means were calculated regarding the effectiveness of ways to reduce bullying, and then rank-ordered. Means for the immediate and 1-month post program designations were averaged and compared with the means for the pre-program selections. 


\section{Findings}

\subsection{Description of sample}

Eleven school nurses from ten schools in three school districts in Western Massachusetts participated. Ten of the eleven school nurses had at least a bachelor's degree in nursing or another discipline and six were certified school nurses. Years as a nurse ranged from 5-40 and years as a school nurse ranged from 2 to 23. Most nurses worked in rural public schools and one worked in a private school. Only one did not work full time and all were Caucasian.

\subsection{Bullying as a problem}

Answering on a scale of 1-7, bullying was thought to be a moderate problem in US schools before and after the program, with means of 4.7 and 5 respectfully. The mode was a score of 4 prior to the program, and 6 after the program. Bullying in their own schools was thought to not be a problem both prior to and following the program with a mean of 3.5 prior to and immediately following the program and a mode of 3 prior to and immediately following the program.

\subsection{Dealing with a bully}

The nurses were asked, "How would you deal with a student who was involved with bullying another student?” Ten possible methods were offered in the questionnaire and the nurses could select more than one method. Examples are "talking with the bully, encouraging the bully to apologize, and having the parents of the bully and the victim meet to resolve the situation.” Following the training, the total number of methods selected by the 11 nurses increased by 35\% ( $\mathrm{N}=35$ methods prior to the program, and 48/46 immediately and one month following the program). The method of "talking with the bully about appropriate behavior" was selected by less than half the nurses prior to the training, but more than half after the training ( $\mathrm{N}=4$ and 8 respectively). Both before and after the program, none of the nurses selected "I would not deal with this issue; it is not my job."

\subsection{Dealing with a victim}

The nurses were asked, "How would you deal with a student who has been a victim of student bullying?” Eleven methods of dealing with a victim were offered such as encouraging the victim to be more assertive, teaming with the bully and the victim to work out a solution and assessing and documenting injuries. The number of methods the nurses would use to work with a victim increased by 35\% after the program ( $N=49$ prior to the program, and 67/65 immediately and 1 month following the program). Two methods were not selected as ways to deal with a victim before the program, but would be used after the training. They were having parents come to the school to resolve the problem and encouraging the victim to be more assertive. The latter was selected by $64 \%$ of the nurses after the program.

\subsection{Perceived ability to recognize the signs that a student was a bully or victim}

The nurses were asked, "How well do you believe you can recognize the signs of a student being a bully?” and the same question was asked pertaining to victims. Their perceptions were measured using a 7-point Likert Scale (see Figure 1). Prior to program, the mode and mean of recognizing a bully was 3 and 3.3 respectively. One month after the program, the mode and mean were 5 and 4.8 respectively. The mode and mean of recognizing a victim prior to the program were 3 and 3.3. One month after the program, the mode and mean were 5 and 4.8. Utilizing paired t-tests with SPSS, these changes proved significant at the level of .01.

\subsection{Barriers to dealing with bullying}

The nurses were asked, "What do you believe are the barriers for you dealing with the problem of bullying?" Ten options were given and the nurses could select more than one. The number of barriers decreased one month after the program $(\mathrm{N}=27, \mathrm{~N}=28$ immediately following the program and $\mathrm{N}=24$ one month after the program). The three most common 
barriers noted before and after the program were that bullying occurred in places not supervised by nurses, a feeling that others are more qualified and not having enough time.

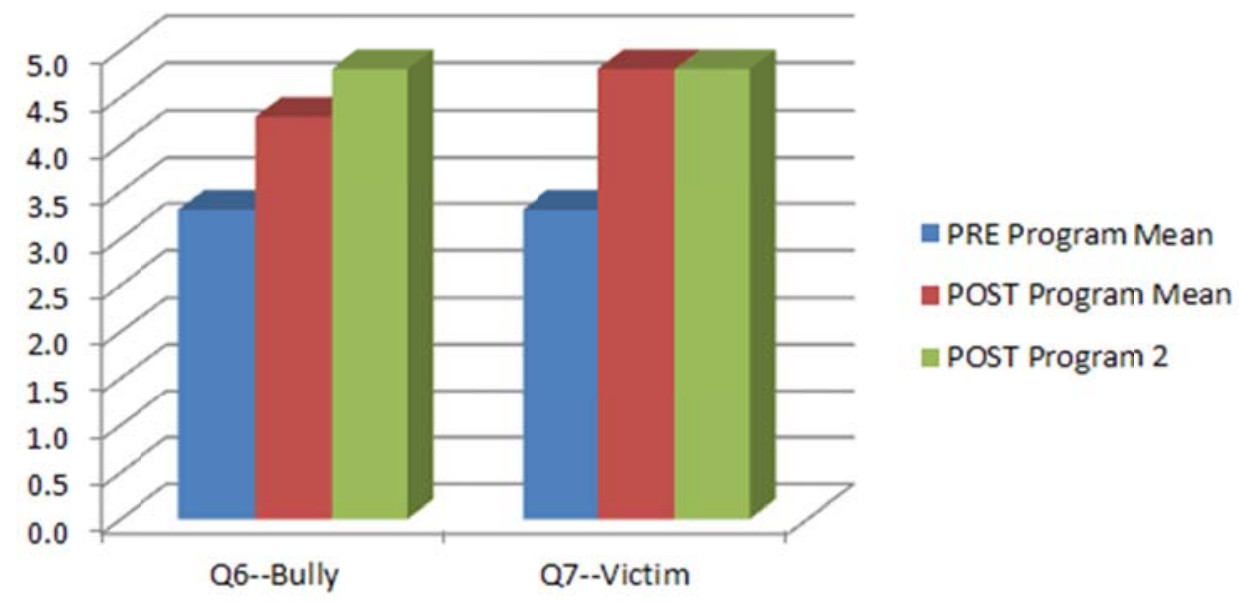

Figure 1. Perceived ability to recognize signs of being a bully and a victim*

"Mean scores are based on a 7-point Likert Scale with 7 being "Very Well”.

\subsection{Methods to reduce bullying}

The questionnaire asked nurses to rate the effectiveness of 35 methods to reduce bullying on a 5-point Likert Scale. Prior to the program, only three methods of reducing bullying were considered effective by the nurses: improving supervision at lunch and recess, having consistent and appropriate discipline responses to violations of anti-bullying policies, and helping the victim to grow in self-appreciation, self-awareness and self-confidence (see Table 1). No methods were considered very effective, 28 methods were considered somewhat effective and four were considered minimally effective. Following the program, 14 methods were considered effective ways to reduce bullying and the rest were considered somewhat effective (see Table 1). One method was ranked as being very effective: establishing positive consequences for students who help prevent bullying problems by intervening or reporting them.

The mean score of perceived effectiveness increased for 33 of the 35 methods. Three methods received nearly a full point increase in their perceived effectiveness: establishing positive consequences for students who help prevent bullying problems, establishing negative consequences for students who bully others and improving supervision for those who walk to school. Meeting with the bully, victim and parents to discuss the problem was perceived as less effective following the program.

\section{Discussion}

Following this educational program all of the nurses reported an increase in their ability to recognize the signs and symptoms of students who are bullies and victims. They also indicated an increase in the number of methods they felt were effective in reducing bullying. This suggests considerable empowerment because of the knowledge gained during the program. In an evaluation of the BVIIP program, the nurses indicated a greater likelihood of aiding victims of bullying as a result of the program.

A greater percentage of the nurses rated bullying as a major public health problem in US schools than in the study by Hendershot and colleagues (33\% vs. 26.2\%). A small sample size, the passage of time and increasing awareness may have influenced this result. Only one nurse in the BVIIP rated bullying as a major problem in her school prior to the program (a score of 6/7). This is similar to Hendershot's results. However, after the program none of the nurses rated it as highly. This 
may reflect a shift in perception related to the presentation of statistical data regarding bullying involvement rather than one generated by personal experience or media attention.

Table 1. Ranked mean scores ${ }^{*}$ of perceived effectiveness of ways to reduce bullying pre and post program ${ }^{\#}$

\begin{tabular}{|c|c|c|}
\hline & PRE & POST \\
\hline (35) Work with victims to lose weight & 2.7 & 3.3 \\
\hline (34) Refer victim to websites & 2.8 & 3.4 \\
\hline (33) Talking with bully—stopping & 2.8 & 3.5 \\
\hline (32) Contact parents of BULLY & 2.9 & 3.1 \\
\hline (31) Negative consequences for bullies & 3.1 & 4.1 \\
\hline (30) Assist students—sudden behavioral changes & 3.1 & 3.6 \\
\hline (29) Give victim printed information & 3.1 & 3.4 \\
\hline (28) Contact parents of VICTIM & 3.1 & 3.6 \\
\hline (27) Talk with victim—prevent future episodes & 3.2 & 3.9 \\
\hline (26) Improve supervision-walkers & 3.2 & 4.1 \\
\hline (25) Meet with bully, victim and parents to discuss the situation and potential solutions & 3.2 & 3.0 \\
\hline (24) Postive consequences for students who help prevent bullying & 3.3 & 4.6 \\
\hline (23) Deal with personal feelings about bullying & 3.3 & 3.7 \\
\hline (22) Assist students—avoiding previous enjoyable activities & 3.3 & 3.7 \\
\hline (21) Document students’ non-specific physical complaints & 3.3 & 3.7 \\
\hline (20) Meetings to tell parents and teachers re: bullying prevention efforts & 3.4 & 3.9 \\
\hline (19) Talk with victim about who could best help & 3.4 & 3.8 \\
\hline (18) Report data on number of victims coming to nurse's office & 3.5 & 3.6 \\
\hline (17) Prog at school for students, parents, comm. Members to raise awareness & 3.5 & 4.0 \\
\hline (16) Utilize student contracts against bullying & 3.5 & 3.7 \\
\hline (15) Classroom rules against bullying & 3.5 & 4.3 \\
\hline (14) Assist students with worsened academics & 3.6 & 3.7 \\
\hline (13) Assist students with increased absenteeism & 3.6 & 3.6 \\
\hline (12) Improve supervision—gym & 3.6 & 4.3 \\
\hline (11) Work with victims—-social skills & 3.6 & 3.7 \\
\hline (10) Establish a bullying prevention committee & 3.7 & 4.2 \\
\hline (9) Improve supervision—hallways & 3.7 & 4.4 \\
\hline (8) Tell students to come to nurse’s office if being bullied & 3.7 & 4.1 \\
\hline (7) Refer victim to school counselor, teacher, child care team & 3.7 & 3.9 \\
\hline (6) Educate victim about the bully/victim dynamic & 3.8 & 4.0 \\
\hline (5) Estab. Peer support groups & 3.8 & 3.9 \\
\hline (4) Improve supervision-bus & 3.9 & 4.3 \\
\hline (3) Improve supervision—-lunch and recess & 4.0 & 4.4 \\
\hline (2) Consistent and appropriate discipline responses to violations & 4.1 & 4.4 \\
\hline (1) Help victim grow in self appreciation, awareness, esteem, confidence & 4.2 & 4.3 \\
\hline
\end{tabular}

*Means were calculated 5-point Likert scale.

"Post program scores represent the average of the scores immediately following and 1 month after the program. 
The National Association of School Nurses and the American Academy of Pediatrics support the role of nurses in preventing school violence and bullying ${ }^{[23,24]}$. Raskauskas and Stoltz agree that school nurses may be in the best position to identify those involved by virtue of their somatic symptoms and absenteeism ${ }^{[30]}$. School nurses should receive training specific to their role in assessing and intervening with bullies and victims. Nurses should be taught how to recognize victims and bullies by their symptoms and learn techniques to intervene that can be easily implemented in the health office.

School nurses act as the entry point for students involved in bullying. Collecting and reporting the number of office visits related to bullying is essential in documenting the extent of a problem within a school system. Nurses should receive administrative support to develop an accurate and consistent documentation system. This data, as well as information regarding the effectiveness of their interventions, could strengthen school-wide efforts and support grant applications to implement bullying prevention programs. School nurses should be encouraged to participate in school violence task forces, and to utilize the resources within and outside the school system, such as websites, national organizations and community agencies, in order to broaden their education about their role in preventing bullying.

Further research should correlate the presentation of specific health symptoms with gender and frequency of bullying in order to more fully understand who reports to the school health office. A screening tool to identify both bullies and victims based on somatic symptoms should be utilized, and the effectiveness of interventions by school nurses should be evaluated.

\section{References}

[1] Robers S, Kemp J, Truman J, Snyder T. Indicators of School Crime and Safety[Internet]. 2012[cited 2013]. Available from: http://nces.ed.gov/pubs2013/2013036.pdf

[2] Sourander A, Ronning J, Brunstein-Klomek A, Gyllenberg D, Kumpulainen K, Niemela S, Helenius H, Sillanmaki L, Ristkari T, Tamminen T, Moilanen I, Piha J, Almqvist F. Childhood bullying behavior and later psychiatric hospital and psychopharmacologic treatment. Arch Gen Psychiatry. 2009 Sept; 66 (9): 1005-1012. PMid:19736357 http://dx.doi.org/10.1001/archgenpsychiatry.2009.122

[3] Sourander A, Jensen P, Ronning J, Niemela S, Helenius H., Sillanmaki L, Kumpulainen K, Piha J, Tamminen T, Moilanen I, Almqvist F. What is the early adulthood outcome of boys who bully and are bullied in childhood? The Finnish "From Boy to a Man” Study. Pediatrics. 2007 Aug; 120(2):397-404. PMid:17671067 http://dx.doi.org/10.1542/peds.2006-2704

[4] Olweus D. Bullying at school and later criminality: Findings from three Swedish community samples of males. Criminal Behaviour and Mental Health. 2011; 21(2): 151-156. PMid:21370301 http://dx.doi.org/10.1002/cbm.806

[5] Ericson N. Addressing the problem of juvenile bullying. US Department of Justice OJJDP Fact Sheet \#27[Internet]. 2001 June. Available from: https://www.ncjrs.gov/pdffiles1/ojjdp/fs200127.pdf

[6] Williams K., Guerra N. Prevalence and predictors of internet bullying. The Journal of Adolescent Health. 2007;41:S14-S21. PMid:18047941 http://dx.doi.org/10.1016/j.jadohealth.2007.08.018

[7] Glew G, Fan M, Katon W, Rivara F, Kernic M. Bullying, Psychosocial Adjustment, and Academic Performance in Elementary School. Arch Pediatric Adoles. Med. 2005 Nov; 159: 1026-1031.

[8] Nansel TR., Overpeck M, Pilla RS, Ruan WJ, Simons-Morton B, Scheidt P. Bullying Behaviors Among US Youth: Prevalence and Association With Psychosocial Adjustment. JAMA. 2001 April 25; 285(16): 2094-2100. PMid:11311098 http://dx.doi.org/10.1001/jama.285.16.2094

[9] Rigby K, Johnson, B. Innocent Bystanders? Teacher. 2004: 38-40. Available from: http://legacy.canadiansafeschools.com/content/documents/Link/Innocent-bystanders-ridby.pdf

[10] Wang J, Iannotti R, Nansel T. School bullying among adolescents in the United States: Physical, verbal, relational and cyber. Journal of Adolescent Health. 2009; 45: 368-375. PMid:19766941 http://dx.doi.org/10.1016/j.jadohealth.2009.03.021

[11] World Health Organization. Health behaviour in school-aged children: International report from the 2005/2006 survey[Internet]. 2008. Available from: http://www.euro.who.int/_data/assets/pdf_file/0005/53852/E91416.pdf

[12] Centers for Disease Control. Youth Risk Behavior Surveillance-United States, 2011. Morbidity and Mortality Weekly Report. 2012; 61: 1-168. 
[13] Klomek A., Marrocco F, Kleinman M, Schonfeld I, Gould M. Bullying, Depression and Suicidality in Adolescents. Journal of the American Academy of Child \& Adolescent Psychiatry. 2007; 46(1): 40-49. PMid:17195728 http://dx.doi.org/10.1097/01.chi.0000242237.84925.18

[14] Camodeca M, Goosens F. Aggression, social cognitions, anger and sadness in bullies and victims. Journal of Child Psychology and Psychiatry. 2005; 46(2): 186-197. PMid:15679527 http://dx.doi.org/10.1111/j.1469-7610.2004.00347.x

[15] Cooper GD, Clements PT, Holt KE. Examining childhood bullying and adolescent suicide:implications for school nurses. J Sch Nurs. 2012; 28(4): 275-283. PMid:22333524 http://dx.doi.org/10.1177/1059840512438617

[16] Janssen I, Craig W, Boyce W. Pickett W. Associations Between Overweight and Obesity With Bullying Behaviors in School-Aged Children. Pediatrics. 2004; 113: 1187-1194. PMid:15121928 http://dx.doi.org/10.1542/peds.113.5.1187

[17] Griffiths L, Wolke D, Page A, Horwood J. Obesity and bullying: different effects for boys and girls. Archives of Disease in Childhoood. 2006; 91: 121-125. PMid:16174642 http://dx.doi.org/10.1136/adc.2005.072314

[18] Wang J, Iannotti R, Luk J. Bullying victimization among underweight and overweight US youth: Differential associations for boys and girls. Journal of Adolescent Health. 2010; 47: 99-101. PMid:20547298 http://dx.doi.org/10.1016/j.jadohealth.2009.12.007

[19] Van Cleave J, Davis M, Bullying and peer victimization among children with special health care needs. Pediatrics. 2006; 118: 1213-e1219. PMid:17015509 http://dx.doi.org/10.1542/peds.2005-3034

[20] Friedman M, Koeske G, Silvestri A, Korr W, Sites E. The impact of gender-role nonconforming behavior, bullying, and social support on suicidality among gay male youth. Journal of Adolescent Health. 2006; 38: 621-623. PMid:16635780 http://dx.doi.org/10.1016/j.jadohealth.2005.04.014

[21] Vernberg E, Nelson T, Fonagy P, Twemlow S. Victimization, agression, and visits to the school nurse for somatic complaints, illnesses, and physical Injuries. Pediatrics. 2011; 127(5): 842-848. PMid:21518714 http://dx.doi.org/10.1542/peds.2009-3415

[22] Greco L, Freeman M, Lynette D. Overt and relational victimization among children with frequent abdominal pain: Links to social skills, academic functioning and health service use. Journal of Pediatric Psychology. 2007; 32(3): 319-329. PMid:16840792 http://dx.doi.org/10.1093/jpepsy/jsl016

[23] Olweus D. Bullying at School: What we know and what we can do. Oxford: Blackwell Publishers, Inc. 1993.

[24] National Association of School Nurses. Position Statement: Role of the school nurse[Internet]. 2011. Available from: http://www.nasn.org/PolicyAdvocacy/PositionPapersandReports/NASNPositionStatementsFullView/tabid/462/ArticleId/87/Role -of-the-School-Nurse-Revised-2011

[25] American Academy of Pediatrics, Council on School Health. Policy Statement: The role of school nurse in providing school health services. Pediatrics. 2008; 121: 1052-1056. PMid:18450912 http://dx.doi.org/10.1542/peds.2008-0382

[26] Hendershot C, Dake J, Price J, Lartey G. Elementary School Nurses’ Perceptions of Student Bullying. The Journal of School Nursing. 2006; 22(4): 229-235. PMid:16856778 http://dx.doi.org/10.1177/10598405050220040801

[27] National Cancer Institute. Theory at a Glance: A guide for health promotion practice (2nd ed.)[Internet]. 2005. Available from: http://www.cancer.gov/cancertopics/cancerlibrary/theory.pdf

[28] Smedley BD, Syme SL (Eds.). Institute of Medicine. Promoting Health: Strategies from Social and Behavioral Research. Washington, D.C. National Academies Press. 2000.

[29] Siegel W, Yates C. Improving the evaluation of professional development presentations using retrospective pre-testing of existing knowledge and self-efficacy. Connexions module: m14362. 2007. Available from: http://cnx.org/content/m14362/latest/

[30] Raskauskas J, Stoltz A. Identifying and intervening in relational aggression. The Journal of School Nursing. 2004; 20 (4): $209-215$. http://dx.doi.org/10.1177/10598405040200040501 